\title{
Characteristics of patients co-infected with HIV at the time of inpatient tuberculosis treatment initiation in Yaoundé, Cameroon: a tertiary care hospital-based cross-sectional study
}

Ako A Agbor ${ }^{1}$, Jean Joel R Bigna ${ }^{2 *}$, Claudia S Plottel ${ }^{3,4}$, Serges Clotaire Billong ${ }^{1,5}$, Mathurin Cyrille Tejiokem Gabriel L Ekali, Jean Jacques N Noubiap ${ }^{7,9}$, Roselyne Toby ${ }^{8}$, Hermine Abessolo ${ }^{8}$ and Sinata Koulla-Shiro ${ }^{1,8}$

\begin{abstract}
Background: Knowledge of the characteristics of patients co-infected with tuberculosis (TB) and human immunodeficiency virus (HIV) when TB treatment is initiated would allow clinicians to improve care and help policy-makers develop relevant and realistic guidelines. The aim of this study was to describe socio-demographic, clinical, and laboratory characteristics of TB/HIV co-infected patients starting inpatient TB treatment in Yaoundé, Cameroon.

Methods: We conducted a retrospective cross-sectional study, collecting data from medical records of HIV-infected patients with TB, aged 15 years old or more, hospitalized in the Infectious Diseases Unit of the Yaoundé Central Hospital, Cameroon from January 1, 2006 to June 30, 2013.

Results: The mean age of 337 patients meeting study inclusion criteria was 39.3 years. More than half were female (53.4\%). Most (89.3\%) resided in urban areas, $44.2 \%$ had a secondary education, and $46.0 \%$ were married. The majority was receiving co-trimoxazole prophylaxis (79.5\%), and two thirds were taking antiretroviral therapy (67.4\%). The mean duration of known HIV infection before TB treatment was 8.4 months. Most (88.1\%) had newly diagnosed TB, rather than relapsed disease. Smear-positive pulmonary TB was documented in a third, (35.3\%). Laboratory data revealed a median white blood cell count of 5,100 cells $/ \mathrm{mm}^{3}$ (IQR 3,300-7,990 cells $/ \mathrm{mm}^{3}$ ), a median hemoglobin level of $8 \mathrm{~g} / \mathrm{dl}$ (IQR 7-10 g/dl), and a median CD4 cell count of 102 cells $/ \mathrm{mm}^{3}$ (IQR 33-178 cells $/ \mathrm{mm}^{3}$ ). Sex differences in our study included older age in the men $(p<0.001)$, more of whom were married $(p<0.001)$ and had achieved a higher level of education $(p=0.042)$. Men had fewer diagnoses of smear-positive pulmonary TB $(p=0.020)$. They weighed more than the women ( $p=0.001$ ) and had higher hemoglobin levels ( $p=0.003$ ).

Conclusions: Suboptimal adherence to WHO treatment recommendations in our Cameroonian study reinforces the importance of prescribing co-trimoxazole in HIV infection and ART for all TB/HIV co-infected persons. We urge that Ministries of Health continue implementing and disseminating guidelines for management of TB/HIV co-infected patients, and we call for measures ensuring that healthcare facilities' stocks of ART and co-trimoxazole are sufficient to meet the need for both.
\end{abstract}

Keywords: Tuberculosis, AIDS, HIV, Cameroon, Profile, TB \& HIV co-infection, Resource-limited setting, Co-morbidities, TB

\footnotetext{
* Correspondence: bignarimij@yahoo.fr

${ }^{2}$ Goulfey Health District, Goulfey, Cameroon

Full list of author information is available at the end of the article
} 


\section{Background}

The Word Health Organization (WHO) estimates that the prevalence of tuberculosis (TB) in 2010 reached 12 million cases, corresponding to rates of 169 per 100,000 population worldwide and to 303 per 100,000 in Africa [1]. The Centers for Disease Control (CDC) point out that worldwide, approximately one third of persons are infected with Mycobacterium tuberculosis [2] underscoring the enormity of the global burden of TB. In most persons, TB infection remains latent and clinically quiescent; however in others, TB progresses and leads to active, infectious TB illness. The millennium development goals for global TB control are to halt and then, to begin reversing the increasing incidence of $\mathrm{TB}$ in order to halve the 1990 prevalence and death rates by 2015 [3]. Cameroon most recently recorded a total of 26,110 cases of TB nationally, with 15,080 new smear-positive cases, corresponding to rates of 124 and 73 per 100,000 population respectively [4]. The rate of successful tuberculosis treatment has been progressively increasing in Cameroon, from $72 \%$ in 2003 to $80 \%$ in 2013 [4].

People living with human immunodeficiency virus (HIV) are much more likely to develop active TB than those who are HIV-negative [1]. The greatest burden of combined TB and HIV infections is seen in sub-Saharan Africa, where the extent of the problem is tragically, inversely proportional to the paucity of resources available for effective control and treatment. Although sub-Saharan Africa has borne the brunt of TB/HIV co-infection and its consequences to date, other parts of the world are increasingly struggling with increasing TB and HIV-related morbidity and mortality as well. HIV infection is frequent among patients with active TB in Cameroon and disproportionately affects women [5,6]. Studies in Cameroon indicate that the HIV infection rate among TB patients has been rapidly increasing, from $16.6 \%$ in 1997 [7] to $51.6 \%$ in 2012 [8]. Recent estimates from CDC taking into account the fact that TB detection and reporting data from sub-Saharan Africa are often incomplete (underestimates), project that there will be 19,000 new HIV-positive TB patients in Cameroon alone in 2013 [2]. Reports from the Cameroonian Ministry of Public Health reveal that in 2013, 82\% of patients known to have TB had also been tested for HIV; of those tested, 38\% were HIV-infected; and of those co-infected with TB and HIV, 65\% were being treated concurrently for both TB and HIV [4].

Despite the encouraging mortality figures from TB occurring in the setting of HIV, better knowledge and understanding of the presentation of TB/HIV co-infected patients at the time of TB diagnosis would allow clinicians to improve their care and would help policy makers in developing targeted guidelines. The aim of this cross-sectional study was thus to describe sociodemographic, clinical, and laboratory characteristics of
TB/HIV co-infected patients at the time of TB diagnosis and treatment initiation in Yaoundé, Cameroon.

\section{Methods}

\section{Study design and setting}

The study was approved by Review Board of the Faculty of Medicine and Biomedical Sciences, University of Yaoundé 1. Written informed consent was obtained from the patient for the inclusion in this study. The retrospective, cross-sectional study focused on baseline characteristics of TB/HIV co-infected patients at the time when anti-tuberculous treatment was initiated. Data was collected from medical records in the Infectious Disease Unit (IDU) of the Yaoundé Central Hospital $(\mathrm{YCH})$, Cameroon. The $\mathrm{YCH}$ houses an accredited treatment center, which is a major treatment center for HIV-infected patients in Cameroon. IDU of $\mathrm{YCH}$ manages $2 \%$ of all the TB cases in Cameroon annually [9]. All diagnosed TB cases are prescribed standard TB regimens and followedup, with outcomes reported according to national TB control guidelines [9].

\section{Study population}

TB cases were identified in the Tuberculosis Reporting Register of the IDU of the $\mathrm{YCH}$, which is the official system for mandatory reporting of $\mathrm{TB}$ cases in the hospital. TB reporting is mandatory nationwide for new cases, relapses, and reentries after treatment dropout. All patients entered in the Register from January 1, 2006 to June 30, 2013 were evaluated for inclusion in the study. We included HIV-infected patients with TB, aged 15 years old or older.

\section{Data collection}

We collected data from the TB registry of the IDU-YCH, from the hospitalization registry of the IDU, from medical records of hospitalized TB/HIV co-infected patients, and from the TB yellow cards of TB/HIV co-infected patients. A TB yellow card is a document on A4 format paper [9] used in anti-tuberculosis treatment. It contains the following information: the patient's name, sex, age, addresses, TB localization, type of TB at treatment initiation, HIV status, and a calendar with check boxes for each day of taking anti-TB drugs.

We collected socio-demographic data including: age, sex, marital status, highest level of education, and residence. We also collected relevant clinical data. Patients were classified by the physician-in-charge of the CDT according to features of their clinical TB presentation, using the WHO standard international definitions [1] as one of the following: smear-positive pulmonary $T B$ (Acid-fast bacilli [AFB] originally found in at least two sputum specimens), smear-negative pulmonary TB (persistence of negative result of three sputum examinations 
after ten days of non-specific antibiotic treatment in a patient with clinical and radiographic signs suggesting pulmonary TB without other obvious cause), and extrapulmonary $T B$ (a patient in whom $\mathrm{TB}$ was found in organs other than the lungs [e.g. pleura, lymph nodes, abdomen, genitourinary tract, skin, joints and bones, meninges]). Extra-pulmonary $T B$ lies for the most part on the clinical decision based on suggestive clinical signs and evidence of a predominantly lymphocytic exudate as in the case of peritoneal TB with ascites or granulomatous lesions on histopathological examination of lymph nodes or other pieces of tissue obtained by biopsy. We defined as "mixed form" all presentations in which a patient had evidence of both pulmonary TB and extra-pulmonary TB. The WHO standard international definitions [1] were further used to categorize each person's TB status at diagnosis: as either a new case or a retreatment case. Other clinical variables recorded from patients' medical records included body weight; the presence of other AIDS-related opportunistic infections from clinical stages 2 to 4 as defined by WHO [10]; occurrence of non-TB and non-HIV related comorbidities the most frequent being non-AIDS defining bacterial infections, malaria, diabetes, and hypertension; information on treatment outcomes; and whether or not the patient received Co-trimoxazole Prophylactic Therapy (CPT) and Anti-Retroviral Therapy (ART). Laboratory data included CD4 cell counts, hemoglobin level, and white blood cell counts.

\section{Data analysis}

Data was coded, entered, and analysed using the Statistical Package for Social Science (SPSS) version 20.0 for Windows (IBM Corp. Released 2011. IBM SPSS Statistics for Windows, Version 20.0. Armonk, NY: IBM Corp.). We described continuous variables using means (standard deviation $[\mathrm{SD}]$ ) or median (interquartile range [IQR]), and categorical variables using their frequencies (percentages). The chi-square test or Fisher's exact test when appropriate, were used to compare categorical variables, Student's t-test was used to compare means, and the Mann-Whitney $U$ test was used to compare medians. All statistical tests were performed using two-sided tests at a 0.05 level of significance. Multiple imputation method was used to handle missing data, by creating a new data set, which was the average of five data sets of imputed values imputation $[11,12]$. This dataset has been used to compare body weight, CD4 count, hemoglobin level, and white blood cells count regarding sex and TB status at diagnosis.

\section{Results}

Figure 1 presents the flowchart of our study population. Of the 337 patient charts meeting inclusion criteria, we had missing values for weight in 36 records $(10.7 \%$ of

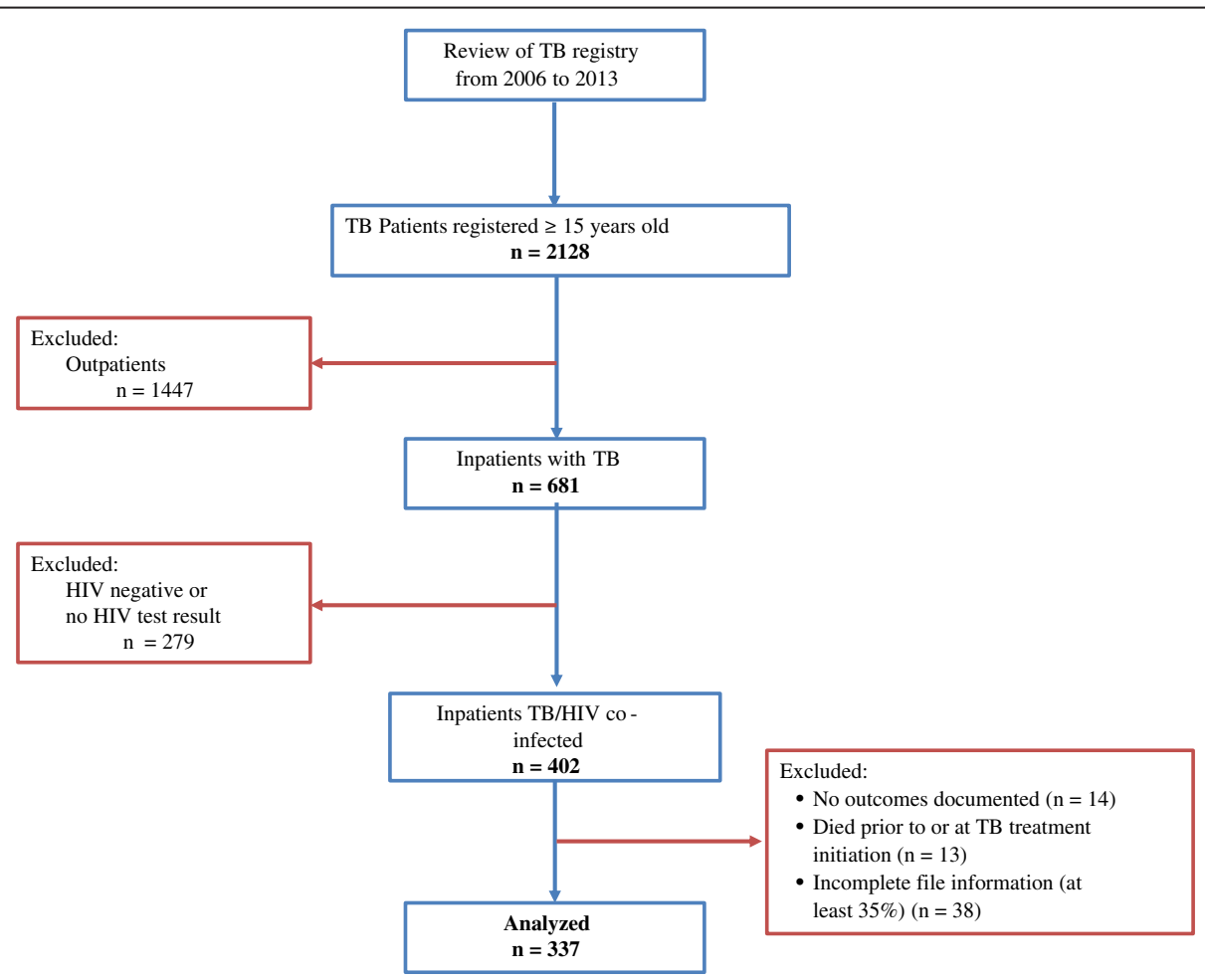

Figure 1 Flowchart for TB/HIV inpatients in the infectious diseases unit of the Yaoundé Central Hospital (2006-2013). 
total), for CD4 counts in 28 records (8.3\% of total), for white blood cell counts in 21 records (6.2\% of total), and for hemoglobin levels in 21 records (6.2\% of total).

\section{Socio-demographic, clinical, and laboratory profile of the study population}

Table 1 presents our study cohort's $(n=337)$ sociodemographic, clinical, and laboratory characteristics. The mean age of our patients was 39.3 years (SD 10.3) and the median was 38 years (IQR 32-46). There were slightly more women than men as $53.4 \%(\mathrm{n}=180)$ were female. The greatest number had attained a secondary level of education $(44.2 \%, \mathrm{n}=149)$. The majority of patients were married $(46.0 \%, n=155)$, closely followed by single status $(44.8 \%, \mathrm{n}=151)$. The median duration of known HIV infection at the time of TB diagnosis was 0.97 (IQR 0.13-5.7) months and the mean was 8.2 (19.0) months. Patients' mean body weight was $52.3 \mathrm{~kg}$ (SD 10.3). Most cases of tuberculosis represented new disease $(88.1 \%, \mathrm{n}=297)$. Most of patients - over one third - had pulmonary TB alone (37.1\%, $n=125)$, closely followed by extra-pulmonary disease $(n=119,35.3 \%)$. Figure 2 details the distribution of the forms of extra-pulmonary tuberculosis in our patients. Lymph nodes (tuberculous lymphadenitis) were the most common extra-pulmonary site, representing a third of all extra-pulmonary tuberculosis $(31.2 \%, n=43)$ in our cohort. Other AIDS-related opportunistic infections and other (non-AIDS and non-TB) comorbidities were present in $53(15.7 \%)$ and $40(11.9 \%)$ patients respectively. Regarding HIV treatment, CPT and ART had been prescribed to $268(79.5 \%)$ and $227(67.4 \%)$ of the patients. The median CD4 count, white blood cells count, and hemoglobin level were $102 \mathrm{cell} / \mathrm{mm}^{3}$ (IQR 33-178), 5,100 cell $/ \mathrm{mm}^{3}$ $(3,300-7,990)$, and $8 \mathrm{~g} / \mathrm{dl}(7-10)$ respectively.

\section{Comparison regarding sex and TB status at diagnosis}

Table 1 includes a comparison of females and males in our study. Regarding socio-demographic characteristics, men were older than women $(p<0.001)$, more were married $(p<0.001)$ and had achieved a higher level of education $(p=0.042)$. As far as their clinical presentation, males had more smear-positive $(\mathrm{PTB}+)$ and smear negative (PTB-) pulmonary TB, less extra-pulmonary TB, and less mixed forms of TB $(p=0.020)$. Men also weighed more than women $(p=0.001)$. On laboratory evaluation, men had higher hemoglobin levels $(p=0.003)$. The patients with recurrent tuberculosis and classified as TB retreatment cases were older than patients with a new diagnosis of TB $(p=0.042)$ and had longer duration of known HIV infection $(p=0.004)$ (Table 2).

\section{Discussion}

The most frequent clinical presentation of patients diagnosed with tuberculosis in the setting of HIV co- infection was that of smear-positive pulmonary TB, just as has been observed from reports of TB and HIV coinfection from other geographic areas outside of subSaharan Africa [13]. The majority of our cases represented newly diagnosed $\mathrm{TB}$ and presented in an advanced state of immune deficiency, with low CD4 T-cell counts. We found low frequencies of AIDS-related opportunistic infections and of other (non-AIDS and non-TB) comorbidities. The extent of CPT and ART in our study is consistent with data recently reviewed and reported by the Centers for Disease Control [2] and fails to achieve the recommended treatment goals of the WHO and the Cameroon's Ministry of Public Health [9].

\section{Socio-demographic profile}

Currently, there is no conclusive evidence of sex-based differences in the occurrence of TB and HIV coinfection in developing countries [6,14-17]. Our study also had a slight preponderance of co-infected women (53.4\%) as compared to men. The apparent sex-based difference is probably related to the high incidence of HIV infection among females in sub-Saharan Africa in general $[17,18]$ and Cameroon in particular $[5,18]$. Women, who have a higher susceptibility to HIV infection [19-21], are usually exposed to sexual activity earlier than men in francophone sub-Saharan Africa, and particularly in Cameroon [22].

In terms of age distribution, the median age was 38 years (IQR 32-46 years) and the mean was 39.3 (SD10.3 years). This is consistent with the findings of other studies [14,23-27]. The TB/HIV co-infection age distribution likely reflects the age-specific prevalence of HIV in the community. This in turn relates to patients' being in a sexually active age group and encountering sexual partners in whom both TB and HIV are prevalent. In our study, the men with $\mathrm{TB}$ and HIV were significantly older than the women. In Cameroon, HIV prevalence is higher in young females compared to young males [5]. Furthermore, the age group most affected by $\mathrm{HIV}$ infection in women is $35-39$ years (HIV prevalence $10.0 \%$ ) and in men is $45-49$ years (HIV prevalence 6.3\%) [5]. Age was also greater among the patients undergoing retreatment of TB as compared to new TB cases. This result is not surprising and is logical, as the passage of time and ageing increase the risk of TB relapse.

In our population, a secondary level of education was the most representative with $44.2 \%$ of patients, although men completed a higher level of education than did women. Our results are consistent with others studies $[5,16,27]$. Findings from a nationwide survey in Cameroon [5] revealed that HIV prevalence is highest among those with primary or secondary $/ 1^{\text {st }}$ cycle education; the same would be thus expected for those with HIV complicated by the emergence of TB. 
Table 1 Socio-demographic, clinical, and laboratory profiles of TB/HIV infected patients in Yaoundé Central Hospital (2006-2013), overall and by sex

\begin{tabular}{|c|c|c|c|c|}
\hline & Male $n=157$ & Female $n=180$ & $p$ & Total $\mathbf{N}=337$ \\
\hline \multicolumn{5}{|l|}{ Socio-demographic profile } \\
\hline Mean age, years & $41.8(9.2)$ & $37.1(10.7)$ & $<.0001$ & $39.3(10.3)$ \\
\hline \multicolumn{5}{|l|}{ Level of education } \\
\hline - No formal & $16(10.2)$ & $32(17.8)$ & .042 & $48(14.2)$ \\
\hline - Primary & $26(16.6)$ & $22(12.2)$ & & $48(14.2)$ \\
\hline - Secondary & $64(40.8)$ & $85(47.2)$ & & $149(44.2)$ \\
\hline - University & $51(32.5)$ & $41(22.8)$ & & $92(27.3)$ \\
\hline \multicolumn{5}{|l|}{ Residence } \\
\hline • Rural & $22(14.0)$ & $14(7.8)$ & .065 & $36(10.7)$ \\
\hline - Urban & $135(86.0)$ & $166(92.2)$ & & $301(89.3)$ \\
\hline \multicolumn{5}{|l|}{ Matrimonial status } \\
\hline - Alone (single/divorced/widower) & 59 (37.6) & $123(68.3)$ & $<.0001$ & $182(54.0)$ \\
\hline - Married & $98(62.4)$ & $57(31.7)$ & & $155(46.0)$ \\
\hline \multicolumn{5}{|l|}{ Clinical profile } \\
\hline \multicolumn{5}{|l|}{ Clinical presentation of TB } \\
\hline - PTB+ only & $48(30.6)$ & $77(42.8)$ & .020 & $125(37.1)$ \\
\hline • PTB- only & $32(20.4)$ & $43(23.9)$ & & $75(22.3)$ \\
\hline • EPTB only & $65(41.4)$ & $54(30.0)$ & & $119(35.3)$ \\
\hline • EPTB + PTB & $12(7.6)$ & $6(3.3)$ & & $18(5.3)$ \\
\hline \multicolumn{5}{|l|}{ TB status at diagnosis } \\
\hline - New & $135(86.0)$ & $162(90.0)$ & .256 & $297(88.1)$ \\
\hline - Retreatment & $22(14.0)$ & $18(10.0)$ & & $40(11.9)$ \\
\hline Mean duration of known HIV infected, months & $10.3(22.1)$ & $6.5(15.8)$ & .076 & $8.2(19.0)$ \\
\hline \multirow[t]{2}{*}{ Mean body weight, $\mathrm{kg}^{*}$} & $55.4(9.7)^{a}$ & $51.5(10.4)^{\beta}$ & .001 & $52.3(10.3)$ \\
\hline & $55.6(9.9)$ & $51.3(10.4)$ & .001 & $53.3(10.4)$ \\
\hline $\begin{array}{l}\text { Presence of another (excluding TB) AIDS } \\
\text { opportunist infections (stage } 2-4 \text { of WHO } \\
\text { classification of HIV infection) }\end{array}$ & $28(17.8)$ & $25(13.96)$ & .321 & $53(15.7)$ \\
\hline $\begin{array}{l}\text { Presence of other comorbidities, non-AIDS } \\
\text { and non-TB }\end{array}$ & $18(11.5)$ & $22(12.2)$ & .830 & $40(11.9)$ \\
\hline Co-trimoxazole prophylactic therapy & $125(79.6)$ & $143(79.4)$ & .969 & $268(79.5)$ \\
\hline Antiretroviral therapy & $112(71.3)$ & $115(63.9)$ & .146 & $227(67.4)$ \\
\hline \multicolumn{5}{|l|}{ Biological profile } \\
\hline \multirow[t]{2}{*}{ Median CD4 count, cell/mm $\mathrm{mm}^{*}$} & $74(27-193)^{\mu}$ & $115(42-172)^{£}$ & .363 & $102(33-178)$ \\
\hline & $75(28-193)$ & $116(43-174)$ & .681 & $103(34-181)$ \\
\hline \multirow[t]{2}{*}{ Median white blood cell count, cell $/ \mathrm{mm}^{3} ¥$} & $5,115(3,300-7,800)^{\pi}$ & $5,100(3,400-8,000)^{\varepsilon}$ & .871 & $5,100(3,300-7,990)$ \\
\hline & $5,100(3250-7800)$ & $5,200(3,300-8,200)$ & .682 & $5,130(3,300-8,000)$ \\
\hline \multirow[t]{2}{*}{ Median hemoglobin level, g/dl ${ }^{*}$} & $9(7-10)^{\pi}$ & $8(6-10)^{\varepsilon}$ & .003 & $8(7-10)$ \\
\hline & $9(7-10)$ & $8(6-10)$ & .002 & $8(7-10)$ \\
\hline
\end{tabular}

Data are mean (standard deviation), $\mathrm{n}(\%)$ and median (interquartile range).

Missing data: ${ }^{\alpha} 20,{ }^{\beta} 16,{ }^{\mu} 10,{ }^{f} 18,{ }^{\top} 7$, and ${ }^{\varepsilon} 11$.

PTB+ and PTB-: smear - positive and -negative pulmonary TB.

EPTB: Extra pulmonary TB.

${ }^{*}$ The row under this variable presents sensitivity analysis after multiple imputation of missing data. 


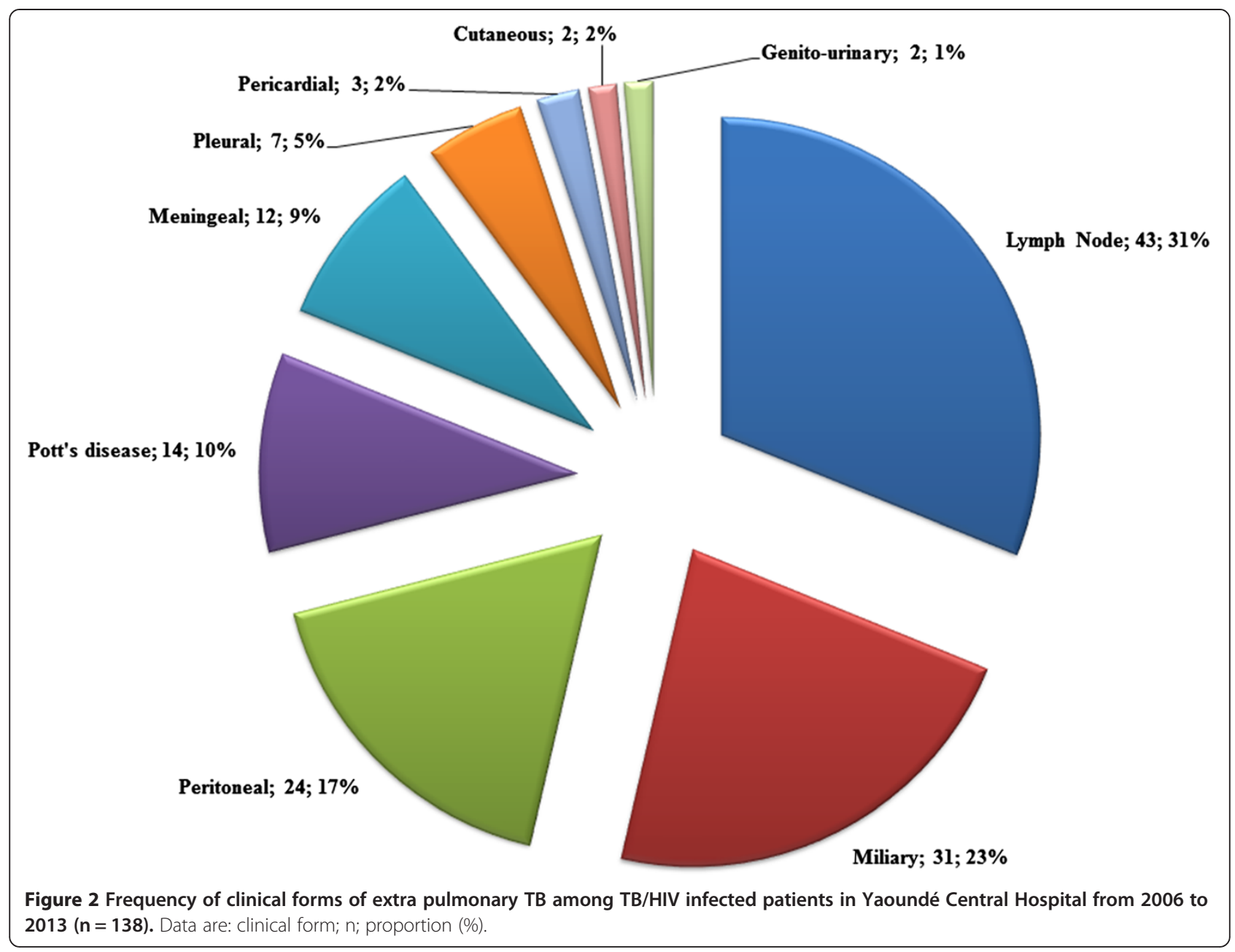

In the present study, the majority of patients (89.3\%) resided in an urban area. Studies, particularly those in sub-Saharan African countries, have shown that the number TB/HIV co-infected cases is higher in urban than rural areas [8]. It is also important to note however, that our study was conducted in a tertiary-care hospital located in an urban area. The Yaoundé area's inhabitants are typical of the urban population of Cameroon.

Almost half of the patients were married (46.0\%). In our study, more men than women were married. There are several possible explanations. A man may be more likely to abandon his wife when she becomes ill (especially in case of HIV infection) and then remarry; also, polygamy is authorized in Cameroon, so if a man is abandoned by one of his wives, he may have others wives and thus stay married. Finally, because of cultural, economic, societal, and religious constraints, women are overall more likely to remain in a marriage than men.

\section{Clinical profile}

In our study, the most frequent clinical presentation of tuberculosis was smear-positive pulmonary disease alone
(37.1\%), followed by extra-pulmonary TB (35.3\%). There have been conflicting reports on the frequency of the various clinical presentations of TB in TB/HIV co-infected patients. Several studies have shown a higher occurrence of smear-negative pulmonary TB $[16,26,28,29]$, while others have shown a high occurrence of extra-pulmonary $\mathrm{TB}$ [30]. Our findings are similar to those of Pefura et al. in Yaoundé, Cameroon [8] and to other studies from Malaysia and Brazil [23,24]. Those reports differ from other published data reporting a greater proportion of smear-negative pulmonary $\mathrm{TB}$ and extra-pulmonary $\mathrm{TB}$ diagnoses in TB/HIV co-infected patients, particularly in a background of advanced immune deficiency (AIDS) where TB tends to present atypically and to more frequently disseminate outside the lung [31]. We acknowledge that one explanation for our results - obtained from a hospital inpatient setting - could be the fact that patients with smear-positive pulmonary TB are more likely than smear negative patients to be hospitalized in order to prevent transmission of the bacilli to others.

Of the 121 (35.9\%) patients with isolated extrapulmonary $\mathrm{TB}$ and 16 (4.7\%) with the mixed clinical 
Table 2 Comparison of socio-demographic, clinical, and laboratory profiles between patients with a new diagnosis of TB and those with retreatment TB in Yaoundé Central Hospital (2006-2013)

\begin{tabular}{|c|c|c|c|}
\hline & $\begin{array}{l}\text { Retreatment } \\
\text { cases } n=40\end{array}$ & $\begin{array}{l}\text { New cases } \\
\mathrm{n}=297\end{array}$ & $p$ \\
\hline \multicolumn{4}{|l|}{$\begin{array}{l}\text { Socio-demographic } \\
\text { profile }\end{array}$} \\
\hline Male & $22(55.0)$ & $135(45.5)$ & .256 \\
\hline Mean age, years & $42.4(8.6)$ & $38.9(10.4)$ & .042 \\
\hline \multicolumn{4}{|l|}{ Level of education } \\
\hline - No formal & $5(12.5)$ & $43(14.5)$ & .956 \\
\hline - Primary & $5(12.5)$ & $43(14.5)$ & \\
\hline - Secondary & $18(45.0)$ & $131(44.1)$ & \\
\hline - University & $12(30.0)$ & $80(26.9)$ & \\
\hline \multicolumn{4}{|l|}{ Residence } \\
\hline • Rural & $4(10.0)$ & $32(10.8)$ & 1.0 \\
\hline - Urban & $36(90.0)$ & $265(89.2)$ & \\
\hline \multicolumn{4}{|l|}{ Matrimonial status } \\
\hline $\begin{array}{l}\text { - Alone (single/ } \\
\text { divorced/widower) }\end{array}$ & $17(42.5)$ & $165(55.6)$ & .120 \\
\hline - Married & $23(57.5)$ & $132(44.4)$ & \\
\hline \multicolumn{4}{|l|}{ Clinical profile } \\
\hline \multicolumn{4}{|l|}{$\begin{array}{l}\text { Clinical presentation } \\
\text { of TB }\end{array}$} \\
\hline - PTB+ only & $16(40.0)$ & $109(36.7)$ & .975 \\
\hline • PTB- only & $8(20.0)$ & $65(22.6)$ & \\
\hline - EPTB only & $14(35.0)$ & $105(35.4)$ & \\
\hline • EPTB + PTB & $2(5.0)$ & $16(5.4)$ & \\
\hline $\begin{array}{l}\text { Mean duration } \\
\text { of known HIV infected, } \\
\text { months }\end{array}$ & $22.9(33.6)$ & $6.3(15.2)$ & .004 \\
\hline \multirow[t]{2}{*}{ Mean body weight, $\mathrm{kg}^{*}$} & $53.2(9.5)^{a}$ & $53.2(10.4)^{\beta}$ & .996 \\
\hline & $53.2(9.4)$ & $53.3(10.5)$ & .941 \\
\hline $\begin{array}{l}\text { Presence of another } \\
\text { (excluding TB) } \\
\text { AIDS opportunist } \\
\text { infections (stage } 2 \text { - } 4 \\
\text { of WHO classification } \\
\text { of HIV infection) }\end{array}$ & $4(10.0)$ & $49(16.5)$ & .286 \\
\hline $\begin{array}{l}\text { Presence of another } \\
\text { comorbidities, } \\
\text { no AIDS-no TB }\end{array}$ & $8(20.0)$ & $32(10.8)$ & .114 \\
\hline $\begin{array}{l}\text { Co-trimoxazole } \\
\text { prophylactic therapy }\end{array}$ & $32(80.0)$ & $236(79.8)$ & .937 \\
\hline Antiretroviral therapy & $32(80.0)$ & $195(65.7)$ & .069 \\
\hline
\end{tabular}

Table 2 Comparison of socio-demographic, clinical, and laboratory profiles between patients with a new diagnosis of TB and those with retreatment TB in Yaoundé Central Hospital (2006-2013) (Continued)

\begin{tabular}{|c|c|c|c|}
\hline \multicolumn{4}{|l|}{ Biological profile } \\
\hline \multirow{2}{*}{$\begin{array}{l}\text { Median CD4 count, } \\
\text { cell/mm } \mathrm{mm}^{3}\end{array}$} & $74(19-169)$ & $102(34-181)^{£}$ & .298 \\
\hline & $74(19-169)$ & 105 (35-184) & .238 \\
\hline \multirow{2}{*}{$\begin{array}{l}\text { Median white } \\
\text { blood cell count, } \\
\text { cell/ } / \mathrm{mm}^{3} ¥\end{array}$} & $5,750(3,825-8,045)$ & $5,000(3,290-7,900)^{\varepsilon}$ & .615 \\
\hline & $5,750(3,825-8,045)$ & $5,100(3,260-8,000)$ & .538 \\
\hline \multirow{2}{*}{$\begin{array}{l}\text { Median hemoglobin } \\
\text { level, g/dl }\end{array}$} & $9(7-10)$ & $8(7-10)^{\varepsilon}$ & .846 \\
\hline & $9(7-10)$ & $8(7-10)$ & .802 \\
\hline
\end{tabular}

Data are mean (standard deviation), $\mathrm{n}(\%)$ and median (interquartile range). Missing data: ${ }^{a},{ }^{\beta} 34,{ }^{f} 28$, and ${ }^{\varepsilon} 18$.

PTB+ and PTB-: smear -positive and -negative pulmonary TB. EPTB: Extra pulmonary TB.

${ }^{¥}$ The row under this variable presents sensitivity analysis after multiple imputation of missing data.

form, tubercular lymphadenitis was the most frequent presentation (31.2\%). Our findings are in agreement with others in developing countries [30,32-34]. Indeed, this reflects the profound host immune suppression induced by HIV infection, which facilitates the dissemination of Mycobacterium tuberculosis out of the lungs, via lymphangitic spread [35] and causes the reactivation of infection in extra-pulmonary organs [36]. However, the relative diagnostic ease with which lymph node TB is detected and diagnosed as compared to other forms of extra-pulmonary TB in resource-limited settings such as Cameroon, may be considered as a partial explanation for the higher percentage of lymph node TB.

The median duration of known HIV infection when anti-tuberculous treatment was initiated was 0.97 (IQR 0.13-5.7) months. Apart from TB, $15.7 \%$ of patients had an additional AIDS-related opportunistic disease and $11.9 \%$ had other co-morbid conditions, which were neither TB nor AIDS-related opportunistic diseases or infections. These findings are congruent with those in Malaysia [23] and likely reflect the fact that the occurrence of tuberculosis is the first manifestation of AIDS in most patients.

The median weight of our patients was $53 \mathrm{~kg}$. Very few studies have looked at this variable and our study shows similar findings to the published literature $[23,26]$. Unfortunately, we could not obtain data as body mass index. Weight loss is common in the setting of both TB and HIV infection [37]. In our study, the men's body mass was greater than that of women, which is expected.

At TB treatment initiation, the majority of patients (79.5\%) were receiving CPT. This is higher than the 
coverage observed in several studies [16,25,38]. In Cameroon, CPT is indicated in all cases of TB/HIV coinfection both in adults and children, irrespective of the CD4 cell count level and WHO clinical stage [9]. This implies all the patients in our cohort were eligible for CPT but the complete coverage (100\%) was not attained. The mindset of some clinicians who place more emphasis on prescribing ART, regarded as lifesaving, while unfortunately neglecting CPT might be an explanation for this finding. It may also be possible that busy CDT staff neglected to consistently document adherence to $\mathrm{CPT}$ prescribing in the medical record. The occurrence of insufficient medication supplies and the inadequacy of $\mathrm{CPT}$ stocks at the $\mathrm{CDT}$ requiring patients to obtain medication elsewhere on their own are also possible explanations.

More than half of the patients (67.4\%) had started ART, yet the frequency of ART coverage among TB/HIV co-infected patients remained less than the $80 \%$ coverage target set by the Ministry of Public Health in Cameroon [9]. Despite recommendations of WHO (all HIV-infected patients must be on ART), some clinicians remain reluctant to prescribe ART to their HIV-infected TB patients, due to concerns about overlapping toxicities, pill burden, and immune reconstitution inflammatory syndrome [39]. Nonetheless, the extent of ART coverage for TB/HIV co-infected patients in studies carried out in North-West region in Cameroon [38], in Southwest Ethiopia [26], and in Trinidad and Tobago [25] was less than what we found. One important factor underlying the difference in the extent of coverage is the fact that all our patients were hospitalized, and so, it was easier to administer ART to patients and to and ensure follow-up.

\section{Laboratory profile}

In an immunocompetent host, infection causes elevation of white blood cell counts. In TB/HIV co-infected patients however, as infection progresses, there is depletion of neutrophils and monocytes by Mycobacterium tuberculosis and lymphocytes (CD4 especially) by HIV [40]. In this study, total white blood cell counts were documented prior to TB treatment initiation; the median white blood cell count was 5,100 cells $/ \mathrm{mm}^{3}$ (normal range). A study carried out in Malaysia by Ismail et al. reports similar findings [23].

The median hemoglobin level in our patients was $8 \mathrm{~g} / \mathrm{dl}$, comparable to what Ismail et $a l$. found in their population [23]. In TB patients, anemia may occur as a result of suppression of erythropoiesis by inflammatory mediators [40]. Anemia in HIV-positive patients has an extensive differential diagnosis, which includes lympho-proliferative disorders, abnormal iron metabolism, hemolysis, and bone marrow suppression (especially with zidovudine) [41,42].
Our study found a difference between males and females regarding hemoglobin concentration, as expected. It is well established that the hemoglobin concentration is physiologically lower in women [43].

Our study shows that, at the time of inpatient TB treatment initiation, most patients were at an advanced immune deficiency state as the median CD4 T-cell count was 102 cells $/ \mathrm{mm}^{3}$. This finding is similar to other studies in developing countries $[16,23,25,27,30]$. HIV impairs the host's immune system [44], setting the stage for the emergence of opportunistic infections like TB, as in our study subjects, and further depletion of CD4 cells [45] ultimately leading to illness requiring medical intervention. Altogether, the synergism between HIV and TB is a reflected in the level of CD4 cell counts measured in our patients $[45,46]$.

\section{Limitations}

Our study captured patients undergoing treatment for tuberculosis over a 90-month period, from January 1, 2006 through June 30, 2013. Starting in 2012, guidelines issued by the Cameroonian Ministry of Public Health for prescribing ART changed. Prior to 2012, it was recommended that ART therapy in the setting of HIV be started when the CD4 cell count was less than 200 cells $/ \mathrm{mm}^{3}$; the 2012 revision instead advised starting ART once the CD4 cell count dropped to 350 cells $/ \mathrm{mm}^{3}$. This likely lead to more of our patients being started on ART later in the study period; tuberculosis guidelines however, remained unchanged for the entire period of our study. Some data for body weight, hemoglobin level, white blood cell count, and CD4 count were missing. In those four categories, the range of missing data was between 6.2 and $10.7 \%$. The reasons for the missing data included failure to enter information in the medical treatment records, and the inability for some patients to pay for laboratory evaluations, which were thus not obtained. Whatever the underlying cause, the missing data underscore the challenges of conducting "real-life" clinical research in resource-limited settings, like Cameroon and other sub-Saharan countries. Aggregate data derived from laboratory testing should be interpreted cautiously as technological advances in the measurement of hematological and immunological parameters over the 8 years of our study, with concurrent changes in methodologies and in laboratory equipment preclude making precise comparisons over time. In addition, as some patients had their laboratory examinations performed in settings other than the $\mathrm{YCH}$, including in private laboratories, we could not retrospectively ascertain which autoanalyzers and laboratory equipment were used to perform those exams.

\section{Conclusions}

In a population of hospitalized Cameroonian patients beginning $\mathrm{TB}$ treatment in the setting of HIV co- 
infection, we found that most of the patients were married, lived in urban areas, and had attained a secondary level of education. Women were younger and fewer were married, as compared to the men. The most common $\mathrm{TB}$ presentation was smear-positive pulmonary $\mathrm{TB}$, closely followed by extra-pulmonary TB. Most of our TB cases were new cases; there were few other AIDS-related opportunistic diseases and few non-AIDS related comorbidities. Most patients were at an advanced stage of immunosuppression. Adherence to the $\mathrm{WHO}$ and the Cameroonian Ministry of Public Health recommendations of TB and HIV co-infection was suboptimal and needs to be improved. In the light of this study, we urge clinicians to prescribe ART for all persons co-infected with TB and HIV and to also treat all HIV infected individuals with $\mathrm{CPT}$, as per the most recently issued treatment guidelines. We further recommend that the Ministry of Health continue promoting and implementing guidelines for the best management of HIV-infected patients and especially for those with TB complicating HIV, by targeting all health care personnel in a concerted educational outreach.

\section{Abbreviations}

AIDS: Acquired immune deficiency syndrome; ART: Anti-retroviral therapy; CD4: Cluster of differentiation 4; CDC: Centers for disease control; CDT: Center of diagnosis and therapy; CPT: Co-trimoxazole prophylactic therapy; HIV: Human immunodeficiency virus; IDU: Infectious diseases unit; TB: Tuberculosis;

WHO: World Health Organization; YCH: Yaoundé Central Hospital.

\section{Competing interests}

The authors declare that they have no competing interests.

\section{Authors' contributions}

Conception and Design: AAA, JJRB, SCB, MCT, GLE, and SK-S. Data collection: AAA, HA, RT and SK-S. Data analysis: JJRB. Data interpretation: JJRB, CSP, and SK-S. First draft: AAA and JJRB. Critical revision and review: JJRB, SCB, MCT, GLE, JJNN, CSP, RT, HA, and SK-S. Manuscript editing and copyediting: CSP. All authors approved the final version to publish.

\section{Authors' information}

This study was conducted as part of AAA's MD degree requirement.

\section{Acknowledgments}

We acknowledge and thank the personnel of the Infectious Disease Unit of Yaoundé Central Hospital for their support during data collection.

\footnotetext{
Author details

${ }^{1}$ Faculty of Medicine and Biomedical Sciences, University of Yaoundé 1, Yaoundé, Cameroon. ${ }^{2}$ Goulfey Health District, Goulfey, Cameroon. ${ }^{3}$ Department of Medicine, New York University Langone Medical Center, New York, USA. ${ }^{4}$ Department of Medicine, New York University School of Medicine, New York, USA. ${ }^{5}$ National AIDS Control Committee, Ministry of Public Health, Yaoundé, Cameroon. ${ }^{6}$ Department of Epidemiology and Public Health, Centre Pasteur du Cameroun, Member of International Network of the Pasteur Institutes, Garoua, Cameroon. IInternal Medicine Unit, Edéa Regional Hospital, Edéa, Cameroon. ${ }^{8}$ Infectious Diseases Unit, Yaoundé Central Hospital, Yaoundé, Cameroon. ${ }^{9}$ Medical Diagnostic Center, Yaounde, Cameroon.
}

Received: 10 December 2014 Accepted: 7 March 2015

Published online: 04 May 2015

\section{References}

1. World Health Organization. Global tuberculosis report 2013 [http://apps. who.int/iris/bitstream/10665/91355/1/9789241564656_eng.pdf]

2. Dokubo EK, Baddeley A, Pathmanathan I, Coggin W, Firth J, Getahun H, et al. Provision of antiretroviral therapy for HIV-positive TB patients - 19 countries, Sub-Saharan africa, 2009-2013. MMWR Morbidity and Mortality Weekly Report. 2014;63(47):1104-7.

3. World Health Organization: Global tuberculosis control: WHO report 2011 [http://apps.who.int/iris/bitstream/10665/44728/1/9789241564380_eng. pdf?ua=1]

4. Programme National de lutte contre la Tuberculose: Plan stratégique de lutte contre la tuberculose au Cameroun 2015-2019 [http://www.pnlt.cm/ index.php/documentation/plan-strategique-national/doc_download/18plan-strategique-natinal-tuberculose-cameroun]

5. National Institute of Statistics, Ministry of Economy and Planning of Cameroon, Ministry of Public Health of Cameroon: The 2011 Cameroon Demographic and Health Survey and Multiple Indicators Cluster Survey (DHS-MICS 2011) [http://slmp-550-104.slc.westdc.net/ stat54/downloads/ EDS-MICS/EDSMICS2011.pdf]

6. Pefura Yone EW, Kuaban C, Kengne AP. HIV testing, HIV status and outcomes of treatment for tuberculosis in a major diagnosis and treatment centre in Yaoundé, Cameroon: a retrospective cohort study. BMC Infectious Diseases. 2012;12:190.

7. Kuaban C, Bercion R, Koulla-Shiro S. HIV seroprevalence rate and incidence of adverse skin reactions in adults with pulmonary tuberculosis receiving thiacetazone free anti tuberculosis treatment in Yaoundé, Cameroon. East Afr Med J. 1997;74:474-7.

8. Pefura EW, Kuaban C, Kengne AP. HIV testing, HIV status and outcomes of treatment for tuberculosis in a major diagnosis and treatment centre in Yaoundé, Cameroon: a retrospective cohort study. BMC Infect Dis. 2012;12:190.

9. Programme National de lutte contre la Tuberculose. Guide pour les personnels de santé [http://www.pnlt.cm/index.php/documentation/ rapports-d-activites/cat_view/4-guidetechnique?orderby=dmdatecounter\& ascdesc $=$ DESC]

10. World Health Organization. Interim WHO clinical staging of HIV/AIDS and HIV/AIDS case definitions for surveillance: African Region [http://www.who. int/hiv/pub/guidelines/clinicalstaging.pdf]

11. Rubin D, Schenker N. Multiple imputation in health-care databases: an overview and some applications. Statistics in Medicine. 1991;10(4):585-98.

12. Little RJA, Rubin DB. Statistical analysis with missing data. New York: John Wiley \& Sons; 1987.

13. Rajasekaran S, Mahilmaran A, Annadurai S, Kumar S, Raja K. Manifestation of tuberculosis in patients with human immunodeficiency virus: a large Indian study. Annals of Thoracic Medicine. 2007;2(2):58-60.

14. Kamath R, Sharma V, Pattanshetty S, Hegde MB, Chandrasekaran V. HIV-TB coinfection: Clinico-epidemiological determinants at an antiretroviral therapy center in Southern India. Lung India. 2013;30(4):302-6.

15. Mohamad Z, Niang N. Characteristics of HIV-infected tuberculosis patients in Kota Bharu Hospital, Kelantan from 1998-2001. Southeast Asia J Trop Med Public Health. 2004;35(1):140-3.

16. Sileshi B, Deyessa N, Girma B, Melese M, Suarez P. Predictors of mortality among TB-HIV Co-infected patients being treated for tuberculosis in Northwest Ethiopia: a retrospective cohort study. BMC Infectious Diseases. 2013;13(1):297.

17. UNAIDS: Global Report. UNAIDS report on the global AIDS epidemic 2013 [http://www.unaids.org/en/media/unaids/contentassets/documents/ epidemiology/2013/gr2013/UNAIDS_Global_Report_2013_en.pdf]

18. ICF International. HIV Prevalence Estimates from the Demographic and Health Surveys [http://dhsprogram.com/pubs/pdf/OD65/OD65.pdf]

19. Addo MM, Altfeld M. Sex-based differences in HIV type 1 pathogenesis. The Journal of Infectious Diseases. 2014;209 Suppl 3:S86-92.

20. van Lunzen J, Altfeld M. Sex differences in infectious diseases-common but neglected. The Journal of Infectious Diseases. 2014;209 Suppl 3:S79-80.

21. Yi TJ, Shannon B, Prodger J, McKinnon L, Kaul R. Genital immunology and HIV susceptibility in young women. Am J Reprod Immunol. 2013;69 Suppl 1:74-9.

22. Rwenge JR. Sexual behavioral among adolescents and young people in Subsaharan Africa and related factors. African Journal of Reproductive Health. 2013;17(1):49-66. 
23. Ismail I, Bulgiba A. Predictors of death during tuberculosis treatment in TB/HIV co-infected patients in Malaysia. PLoS One. 2013;8(8):e73250.

24. Domingos MP, Caiaffa WT, Colosimo EA. Mortality, TB/HIV co-infection, and treatment dropout: predictors of tuberculosis prognosis in Recife, Pernambuco State, Brazil. Cad Saude Publica. 2008;24(4):887-96.

25. Mungrue K, Beharry A, Kalloo J, Mahabir S, Maraj T, Ramoutar R, et al. Trends in HIV/TB coinfection in Trinidad and Tobago for the period 1998-2007. J Int Assoc Physicians AIDS Care (Chic). 2009;8(3):170-5.

26. Shaweno D, Worku A. Tuberculosis treatment survival of HIV positive TB patients on directly observed treatment short-course in Southern Ethiopia: a retrospective cohort study. BMC Research Notes. 2012;5:682

27. Deribe K, Yami A, Deribew A, Mesfin N, Colebunders R, Van Geertruyden JP, et al. Predictors of mortality among tuberculosis-HIV-coinfected persons in Southwest Ethiopia: a case-control study. J Int Assoc Prov AIDS Care. 2013. doi:10.1177/2325957413500528

28. Esmael A, Tsegaye G, Wubie M, Endris M. Tuberculosis and human immune deficiency virus Co-infection in debre Markos referral hospital in Northwest Ethiopia: a five years retrospective study. J AIDS Clin Res. 2013;4(12):263.

29. Sebsibe T, Takele T. HIV co-infection among tuberculosis patients in Dabat, northwest Ethiopia. J Infect Dis Immun. 2013;5(3):29-32.

30. Chang-Hoon L, Ji-young H, Dae-Kyu O, Mee-Kyung K, Eunjung O, Jung-wook $A$, et al. The burden and characteristics of tuberculosis/human immunodeficiency virus (TB/HIV) in South Korea: a study from a population database and a survey. BMC Infect Dis. 2010;10:66.

31. Burman W, Jones B. Clinical and radiographic features of HIV-related tuberculosis. Semin Respir Infect. 2003;18:263-71.

32. Perfura-Yone EW, Kengne AP, Balkissou AD, Onana IN, Endale LMM, Amadou D, et al. Clinical forms and determinants of different locations extra-pulmonary tuberculosis in an African country. Indian J Tuberc. 2013;60:107-13.

33. Yone EW, Kengne AP, Moifo B, Kuaban C. Prevalence and determinants of extrapulmonary involvement in patients with pulmonary tuberculosis in a Sub-Saharan African country: a cross-sectional study. Scand J Infect Dis. 2013;45(2):104-11.

34. Horo K, Anon JC, Achi V. Tuberculose extrapulmonaire au centre antituberculeux d'Adjame -Cote d'lvoire. Rev Pneumol Trop. 2011;15:59-68.

35. de-Noronha AL, Bafica A, Nogueira L, Barral A, Barral-Netto M. Lung granulomas from Mycobacterium tuberculosis/HIV-1 co-infected patients display decreased in situ TNF production. Pathol Res Pract. 2008;204:155-61.

36. Lillebaek T, Dirksen A, Vynnycky E, Baess I, Thomsen VO. Stability of DNA patterns and evidence of Mycobacterium tuberculosis reactivation occurring decades after the initial infection. J Infect Dis. 2003;188:1032-9.

37. Semba RD, Darnton-Hill I, de Pee S. Addressing tuberculosis in the context of malnutrition and HIV coinfection. Food and Nutrition Bulletin. 2010;31(4):S345-64.

38. Njozing NB, Miguel SS, Tih PM, Hurtig AK. Assessing the accessibility of HIV care packages among tuberculosis patients in the Northwest Region, Cameroon. BMC Public Health. 2010;10:129.

39. Cain KP, Anekthananon T, Burapat C, Akksilp S, Mankhatitham W, Srinak C, et al. Causes of death in HIV-infected persons who have tuberculosis, Thailand. Emerg Infect Dis. 2009;15(2):258-64.

40. Husain AN. Lung. In: Kumar V, Abbas AK, Aster JC, editors. Robbins Basic Pathology. 9th ed. USA: Elsevier Saunders; 2012. p. 486-504.

41. Morfeldt-Månson L, Bo"ttiger B, Nilsson B, von Stedingk L. Clinical signs and laboratory markers in predicting progression to AIDS in HIV-1 infected patients. Scand J Infect Dis. 1991;23:443.

42. Cleveland R, Liu Y. CD4 expression by erythroid precursor cells in human bone marrow. Blood. 1996;87:2275.

43. Walker BR, Colledge NR, Ralston SH, Penman I. Davidson's principles and practice of medicine. 22nd ed. UK: Elsevier Health Sciences; 2013.

44. Rizzardi GP, Pantaleo G. The immunopathogenesis of HIV-sa1 infection. In: Armstrong D, Cohen J, editors. Infectious diseases. London, UK: Harcourt; 1999. p. 1-12.

45. Day JH, Grant AD, Fielding KL, Morris L, Moloi V, Charalambous S, et al. Does tuberculosis increase HIV load? The Journal of Infectious Diseases. 2004;190(9):1677-84

46. Aaron L, Saadoun D, Calatroni I, Launay O, Memain N. Tuberculosis in HIV-infected patients: a comprehensive review. Clin Microbiol Infect. 2004;10:388-98.

\section{Submit your next manuscript to BioMed Central and take full advantage of:}

- Convenient online submission

- Thorough peer review

- No space constraints or color figure charges

- Immediate publication on acceptance

- Inclusion in PubMed, CAS, Scopus and Google Scholar

- Research which is freely available for redistribution

Submit your manuscript at www.biomedcentral.com/submit 